\title{
Adverse Health Outcomes in Relationship to Hypogonadism After Chemotherapy: A Multicenter Study of Testicular Cancer Survivors
}

\author{
Mohammad Abu Zaid, MDa; Paul C. Dinh Jr, MPHa; Patrick O. Monahan, PhDa; Chunkit Fung, MDb; Omar El-Charif, MSc; \\ Darren R. Feldman, MDd; Robert J. Hamilton, MDe; David J. Vaughn, MD; Clair J. Beard, MDg; Ryan Cook, MPHa; \\ Sandra Althouse, MSa; Shirin Ardeshir-Rouhani-Fard, PharmD, MPH'; Howard D. Sesso, ScD ${ }^{\text {h }}$ Robert Huddart, MBBSi; \\ Taisei Mushiroda, PhDj; Michiaki Kubo, MD, PhDj; M. Eileen Dolan, PhDc; Lawrence H. Einhorn, MDa; \\ Sophie D. Fossa, MD, PhD'; and Lois B. Travis, MD, ScDa; for the Platinum Study Group*
}

\section{ABSTRACT}

Background: This study examined the prevalence of hypogonadism, its clinical and genetic risk factors, and its relationship to adverse health outcomes (AHOs) in North American testicular cancer survivors (TCS) after modern platinum-based chemotherapy. Patients and Methods: Eligible TCS were $<55$ years of age at diagnosis and treated with first-line platinum-based chemotherapy. Participants underwent physical examinations and completed questionnaires regarding $15 \mathrm{AHOs}$ and health behaviors. Hypogonadism was defined as serum testosterone levels $\leq 3.0 \mathrm{ng} / \mathrm{mL}$ or use of testosterone replacement therapy. We investigated the role of 2 single nucleotide polymorphisms (rs6258 and rs12150660) in the sex hormone-binding globulin (SHBG) locus implicated in increased hypogonadism risk in the general population. Results: Of 491 TCS (median age at assessment, 38.2 years; range, 18.7-68.4 years), 38.5\% had hypogonadism. Multivariable binary logistic regression analysis identified hypogonadism risk factors, including age at clinical evaluation (odds ratio [OR], 1.42 per 10 -year increase; $P=.006$ ) and body mass index of 25 to $<30 \mathrm{~kg} / \mathrm{m}^{2}(\mathrm{OR}, 2.08 ; P=.011)$ or $\geq 30 \mathrm{~kg} / \mathrm{m}^{2}$ $(\mathrm{OR}, 2.36$; $P=.005)$ compared with $<25 \mathrm{~kg} / \mathrm{m}^{2}$. TCS with $\geq 2$ risk alleles for the SHBG SNPs had a marginally significant increased hypogonadism risk (OR, 1.45; $P=.09)$. Vigorous-intensity physical activity appeared protective (OR, $0.66 ; P=.07)$. Type of cisplatinbased chemotherapy regimen and socioeconomic factors did not correlate with hypogonadism. Compared with TCS without hypogonadism, those with hypogonadism were more likely to report $\geq 2$ AHOs (65\% vs $51 \%$; $P=.003)$, to take medications for hypercholesterolemia $(20.1 \%$ vs $6.0 \% ; P<.001)$ or hypertension $(18.5 \%$ vs $10.6 \% ; P=.013)$, and to report erectile dysfunction $(19.6 \%$ vs $11.9 \% ; P=.018$ ) or peripheral neuropathy (30.7\% vs $22.5 \% ; P=.041)$. A marginally significant trend for increased use of prescription medications for either diabetes $(5.8 \%$ vs $2.6 \% ; P=.07)$ or anxiety/ depression (14.8\% vs $9.3 \% ; P=.06$ ) was observed. Conclusions: At a relatively young median age, more than one-third of TCS have hypogonadism, which is significantly associated with increased cardiovascular disease risk factors, and erectile dysfunction. Providers should screen TCS for hypogonadism and treat symptomatic patients.

J Natl Compr Canc Netw 2019;17(5):459-468 doi: 10.6004/jnccn.2018.7109

See JNCCN.org for supplemental online content.

\section{Background}

Testicular cancer is the most common cancer among young men (age $18-39$ years). ${ }^{1}$ Currently, $>95 \%$ of patients are cured of the disease. ${ }^{2}$ Although some patients with stage I disease are cured with orchiectomy only, those with advanced or recurrent disease will typically require cisplatin-based chemotherapy. Although testicular cancer survivors (TCS) can now expect to live for $>40$ years after diagnosis, ${ }^{3}$ they are at risk for shortand long-term complications related to cancer therapy, including hypogonadism. ${ }^{4}$

Hypogonadism and its health effects have been largely studied in the general population in older men, because testosterone levels decrease with aging. ${ }^{5-8}$ Hypogonadism has been linked to obesity, high cholesterol levels, cardiovascular disease (CVD), and decreased bone mineral density. ${ }^{9}, 10$ Recent genetic investigations in the general population have identified 2 single nucleotide polymorphisms (SNPs) in the sex hormone-binding globulin gene $(S H B G)$ through genome-wide association studies associated with increased risk for hypogonadism. ${ }^{11}$ No study, however, has examined the prevalence of hypogonadism in North American TCS and its relationship to adverse health outcomes (AHOs).

andiana University, Melvin and Bren Simon Cancer Center, Indianapolis, Indiana; ' ${ }^{-}$nniversity of Rochester Medical Center, James P. Wilmot Cancer Institute, Rochester, New York; ' Department of Medicine, University of Chicago, Chicago, Illinois; ${ }^{d}$ Department of Medical Oncology, Memorial Sloan Kettering Cancer Center, New York, New York; ${ }^{e}$ Division of Urology, Princess Margaret Cancer Centre, Toronto, Ontario; ${ }^{f}$ Department of Medicine, University of Pennsylvania, Philadelphia, Pennsylvania; ${ }^{9}$ Department of Radiation Oncology, Dana-Farber Cancer Institute, and hivisions of Preventive Medicine and Aging, Department of Medicine, Brigham and Women's Hospital, Boston,

Massachusetts; 'The Royal Marsden Hospital, London, United Kingdom; jThe RIKEN Center for Integrative Medical Science, Yokohama, Japan; and kDepartment of Oncology, Oslo University Hospital, Radium Hospital, Oslo, Norway.

*To view members of the Platinum Study Group and Platinum Study Group Advisory Board, see supplemental eAppendices 1 and 2 (available with this article at JNCCN.org). 
Most TCS have had one testicle (or both) surgically removed and have received chemotherapy that can damage the function of the remaining testicle, and thus are already at elevated risk for hypogonadism compared with the general population. In addition, an inherently increased risk may be due to testicular dysgenesis syndrome, a constellation of conditions proposed to also elevate risk of testicular cancer. ${ }^{12-14}$

This study examined the prevalence of AHOs in relationship to hypogonadism among TCS enrolled in the Platinum Study, a multicenter North American investigation of the long-term effects of cisplatin-based chemotherapy. The role of $S H B G$ gene polymorphisms in hypogonadism risk among TCS are also investigated for the first time.

\section{Patients and Methods}

\section{Participants}

The Platinum Study protocol evaluated late consequences of platinum-based chemotherapy and was approved by the Institutional Review Boards at all participating institutions. ${ }^{15}$ Each study participant provided written informed consent allowing access to their medical records since their cancer diagnosis. Eligibility criteria included confirmed diagnosis of germ cell tumor (GCT), age $<55$ years at diagnosis, treatment with first-line platinumbased chemotherapy, no salvage chemotherapy, no radiotherapy, and no antecedent chemotherapy for another primary cancer. All participants were disease-free at the time of clinical evaluation and were undergoing routine follow-up at the participating site. The first 491 consecutively enrolled TCS for whom funding was available to measure serum testosterone were included in this analysis. Participants in this analysis were similar to the first 1,214 survivors enrolled in the Platinum Study ${ }^{16}$ in terms of age at testicular cancer diagnosis $(P=.81)$, age at clinical evaluation for the Platinum Study $(P=.30)$, and other clinical and sociodemographic characteristics (supplemental eTable 1, available with this article at JNCCN.org). Data on the prevalence of metabolic syndrome and its risk factors in this cohort have been previously described. ${ }^{17}$

\section{Assessments}

\section{Patient-Reported Health Outcomes and Lifestyle Behaviors}

TCS completed a questionnaire regarding health outcomes, lifestyle behaviors, and current prescription medications with indications (including antihypertensive, diabetic, and lipid-lowering medications). Each of the following conditions was considered an AHO (definitions provided in supplemental eTable 2): hypercholesterolemia and on prescription medication, hypertension and on prescription medication, erectile dysfunction (ED), diabetes and on prescription medication, psychotropic prescription medications for anxiety and/or depression, CVD, peripheral vascular disease, thromboembolic disease, renal disease, peripheral neuropathy, Raynaud phenomenon, benign thyroid disease, tinnitus, hearing impairment, and problems with balance/vertigo/dizziness. Demographic information included age at cancer diagnosis and at clinical evaluation, race, education, employment, and marital status. Smoking status was categorized as current, former, or never-smoker. Physical activity was reported as the average time per week engaged in various forms of exercise, using validated questionnaires. ${ }^{18}$ Moderate- and vigorous-intensity physical activity were defined as participating in at least 1 activity per week with a metabolic equivalent (MET) of 3 to $<6$ METs or $\geq 6$ METs, respectively. ${ }^{16,19,20}$

\section{Data Collection From Medical Records}

Study staff abstracted data according to a standardized protocol. ${ }^{15,16}$ Collected data included diagnosis date, histology, and site of GCT, and the name, dose, dates of administration, number of cycles, and cumulative dose for each cytotoxic drug. All data were entered into the eClinical system (www.eClinicalWorks.com), supported by the study coordinating center.

\section{Clinical Evaluation}

TCS underwent a brief physical examination, which included measurement of height and weight. Body mass index (BMI) was calculated as $\mathrm{kg} / \mathrm{m}^{2}$. Blood samples were drawn and time of collection was recorded, and the samples were then frozen and shipped to the central laboratory. Serum levels of testosterone were measured using commercial assays. Hypogonadism was defined using the FDA definition (serum testosterone level $\leq 3.0 \mathrm{ng} / \mathrm{mL})^{21}$ or use of testosterone replacement therapy.

\section{DNA Genotyping and Imputation}

DNA was extracted from blood samples collected at clinical evaluation. SNPs were genotyped on the HumanOmniExpressExome-8 BeadChip Kit (Illumina, Inc.) at the RIKEN Center for Integrative Medical Sciences. Because the SNPs of interest are not called on this chip, we performed genotype imputation following standard quality control measures as previously described. ${ }^{22}$ Imputation was performed on the University of Michigan Imputation Server ${ }^{23}$ with the following parameters: 1000 Genomes Phase 1 (version 3) SHAPEIT2 (no singletons) reference panel, SHAPEIT phasing, and the EUR (European) population. SNP calls were converted to risk allele dosage format.

\section{Statistical Analyses}

Data were summarized with median (ranges) for continuous variables and proportions for categorical variables in 2 TCS subgroups defined by the presence or absence of hypogonadism. Variables in the 2 groups were 
compared using the Pearson chi-square and 2-sided Wilcoxon rank sum tests for categorical and continuous variables, respectively. To determine factors associated with hypogonadism in TCS, variables that were significantly different between the 2 groups with regard to clinical, sociodemographic, and other characteristics were included in the multivariable binary logistic regression analysis. Adjusted odds ratios (ORs), 95\% CIs, and $P$ values were reported. Cumulative number of risk alleles in $S H B G$ was also included in the multivariable model due to evidence for its role in the determination of serum testosterone concentrations in the general male population. ${ }^{11}$ All statistical analyses were conducted using SAS 9.4 (SAS Institute Inc.). All tests were 2-sided, with $P<.05$ considered statistically significant.

\section{Results}

Population Characteristics of TCS

A total of 491 TCS were assessed, with a median age at clinical evaluation of 38.2 years (Table 1). In all, 189 TCS (38.5\%) met criteria for hypogonadism. TCS with hypogonadism were significantly older at clinical evaluation than those without hypogonadism (median age, 42.6 vs 36.5 years; $P<.001$ ). Most TCS received bleomycin/ etoposide/cisplatin (BEP; 55.4\%) or etoposide/cisplatin (EP; $32.4 \%$ ), but hypogonadism prevalence did not differ by treatment regimen $(P=.95)$ or cumulative dose of cisplatin or bleomycin ( $P=.99$ and .56 , respectively). TCS with hypogonadism had a significantly higher prevalence of being overweight or obese $(83.1 \%$ vs $69.2 \% ; P<.001)$, and were less likely to participate in vigorous-intensity physical activity ( $56.1 \%$ vs $72.5 \%$; $P<.001$ ) compared with those without hypogonadism.

\section{Factors Associated With Hypogonadism in TCS}

In multivariable binary logistic regression analysis, age at clinical evaluation (OR, 1.42 per 10-year increase in age; 95\% CI, 1.10-1.83; $P=.006$ ) and being overweight (BMI, 25 to $<30 \mathrm{~kg} / \mathrm{m}^{2}$; OR, 2.08; 95\% CI, $1.18-3.66$; $\left.P=.011\right)$ or obese (BMI, $\geq 30 \mathrm{~kg} / \mathrm{m}^{2}$; OR, 2.36; 95\% CI, 1.29-4.31; $P=.005)$ were significantly associated with increased risk for hypogonadism (Table 2). Although significant in bivariate analysis, vigorous-intensity physical activity was only marginally associated with reduced hypogonadism risk (OR, 0.66; 95\% CI, 0.41-1.04; $P=.07$ ) after adjusting for other independent variables in the model. TCS with 2 or 3 risk alleles had a trend for increased risk of hypogonadism compared with TCS with no or 1 risk allele in multivariable analysis (OR, 1.45; 95\% CI, 0.95-2.24; $P=.09$ ).

Association Between Hypogonadism and AHOs Among all 15 AHOs included in the survey, 28\% of TCS with hypogonadism reported $\geq 4$ AHOs compared with
$16 \%$ of those without hypogonadism (Figure 1), and TCS with hypogonadism were less likely to report no or only one AHO (35\%) compared with those without (49\%) $(P=.002)$. Associations between specific AHOs and hypogonadism are shown in Table 3. Compared with TCS without hypogonadism, those with hypogonadism were significantly more likely to take medications for hypercholesterolemia $(20.1 \%$ vs $6.0 \% ; P<.001)$, hypertension $(18.5 \%$ vs $10.6 \% ; P=.013)$, and $\mathrm{ED}(19.6 \%$ vs $11.9 \% ; P=.018$ ), with a marginal trend toward increased use of prescription medications for either diabetes $(5.8 \%$ vs $2.6 \% ; P=.07)$ or anxiety/depression $(14.8 \%$ vs $9.3 \%$; $P=.06)$. TCS with hypogonadism were also significantly more likely to report symptoms of moderate or severe peripheral neuropathy ( $30.7 \%$ vs $22.5 \% ; P=.041)$ compared with those without hypogonadism. As expected, no associations were observed between hypogonadism and several of the AHOs, such as tinnitus and hearing loss.

\section{Association of Genetic Variants in SHBG With Hypogonadism}

We assessed the association of 2 SNPs (rs6258 and rs12150660) in the $S H B G$ locus previously implicated in increased hypogonadism risk in the general population. ${ }^{11}$ SNPs rs 12150660 and rs6258 showed, respectively, high imputation quality $\left(\mathrm{R}^{2}, 0.99\right.$ and 0.87$)$, high call rate $(>99.7 \%$ and $>99.8 \%$ ), and perfect Hardy-Weinberg equilibrium ( $P=.98$ and .97). Because rs6258 is a rare variant (minor allele frequency, $0.69 \%$ ), there were no homozygous minor patients and only 7 heterozygous patients in the cohort. Both SNPs displayed effect sizes similar to those reported previously in the general population (rs6258: OR, 1.6; $P=.5$; rs12150660: OR, 0.79; $P=.28$ ). When the risk for hypogonadism was analyzed according to the cumulative number of risk alleles for rs12150660 (G) and rs6258 (T) (Figure 2), OR per each additional risk allele was 1.26 (95\% CI, 0.91-1.76; $P$ for trend $=.17$ ).

\section{Discussion}

To date, this is the largest investigation of the prevalence of hypogonadism and associated AHOs among North American TCS after treatment with modern cisplatinbased chemotherapy. It is also the first series to investigate the influence of genetic variants in the $S H B G$ gene on hypogonadism risk in TCS. At a median age of only 38 years at clinical evaluation, $>38 \%$ of TCS had low testosterone levels or were on testosterone replacement therapy. Significant risk factors included increasing age and BMI. Although vigorous-intensity physical activity appeared protective and genetic variants in $S H B G$ may have influenced hypogonadism risk, results were of borderline significance. 


\section{Table 1. Patient Characteristics}

\begin{tabular}{|c|c|c|c|c|}
\hline \multirow[b]{2}{*}{ Characteristic } & \multirow{2}{*}{$\begin{array}{l}\text { All Patients } \\
\text { n (\%) }\end{array}$} & \multicolumn{2}{|c|}{ Hypogonadism } & \multirow[b]{2}{*}{$P$ Value $^{a}$} \\
\hline & & Present, n (\%) & Absent, n (\%) & \\
\hline Total & $491(100)$ & $189(100)$ & $302(100)$ & \\
\hline Median age at testicular cancer diagnosis (range), y & $30.6(15.4-49.9)$ & $33.5(15.9-49.9)$ & $29.6(15.4-49.7)$ & $<.001$ \\
\hline \multicolumn{5}{|l|}{ Clinical characteristics } \\
\hline \multicolumn{5}{|l|}{ Age at clinical evaluation for Platinum Study } \\
\hline Median (range), y & $38.2(18.7-68.4)$ & $42.6(20.2-68.4)$ & $36.5(18.7-68.1)$ & $<.001$ \\
\hline$<30 y$ & $101(20.6)$ & $29(15.3)$ & $72(23.9)$ & \multirow{4}{*}{$<.001$} \\
\hline $30-39$ y & $168(34.2)$ & $51(27.0)$ & $117(38.7)$ & \\
\hline $40-49$ y & $139(28.3)$ & $63(33.3)$ & $76(25.2)$ & \\
\hline$\geq 50 y$ & $82(16.7)$ & $46(24.3)$ & $36(11.9)$ & \\
\hline Missing & $1(0.2)$ & 0 & $1(0.3)$ & \\
\hline \multicolumn{5}{|l|}{ Tumor histology } \\
\hline Seminoma & $130(26.5)$ & $63(33.3)$ & $67(22.2)$ & \multirow{2}{*}{.007} \\
\hline Nonseminoma/Mixed & $361(73.5)$ & $126(66.7)$ & $235(77.8)$ & \\
\hline \multicolumn{5}{|l|}{ Tumor site } \\
\hline Testis & $438(89.2)$ & $172(91.0)$ & $266(88.1)$ & \multirow{2}{*}{.32} \\
\hline Extragonadal & $53(10.8)$ & $17(9.0)$ & $36(11.9)$ & \\
\hline \multicolumn{5}{|l|}{ Tumor stage } \\
\hline 1 & $128(26.1)$ & $50(26.5)$ & $78(25.8)$ & \multirow{3}{*}{.66} \\
\hline II & $189(38.5)$ & $74(39.2)$ & $115(38.1)$ & \\
\hline III & $111(22.6)$ & $38(20.1)$ & $73(24.2)$ & \\
\hline Not stated & $63(12.8)$ & $27(14.3)$ & $36(11.9)$ & \\
\hline \multicolumn{5}{|l|}{ Cumulative dose of cisplatin, $\mathrm{mg} / \mathrm{m}^{2}$} \\
\hline$<300$ & $28(5.7)$ & $10(5.3)$ & $18(6.0)$ & \multirow{6}{*}{.99} \\
\hline 300 & $155(31.6)$ & $60(31.7)$ & $95(31.5)$ & \\
\hline $301-399$ & $17(3.5)$ & $7(3.7)$ & $10(3.3)$ & \\
\hline 400 & $265(54.0)$ & $103(54.5)$ & $162(53.6)$ & \\
\hline$>400$ & $23(4.7)$ & $8(4.2)$ & $15(5.0)$ & \\
\hline Received carboplatin & $3(0.6)$ & $1(0.5)$ & $2(0.7)$ & \\
\hline \multicolumn{5}{|l|}{ Cumulative dose of bleomycin, IU } \\
\hline 0 & $198(40.3)$ & $72(38.1)$ & $126(41.7)$ & \multirow{5}{*}{.56} \\
\hline$>0-180,000$ & $37(7.5)$ & $18(9.5)$ & $19(6.3)$ & \\
\hline $181,000-270,000$ & $183(37.3)$ & $69(36.5)$ & $114(37.7)$ & \\
\hline $271,000-360,000$ & $72(14.7)$ & $30(15.9)$ & $42(13.9)$ & \\
\hline$>360,000$ & $1(0.2)$ & $0(0)$ & $1(0.3)$ & \\
\hline
\end{tabular}

Abbreviations: BEP, bleomycin/etoposide/cisplatin; EP, etoposide/cisplatin; METs, metabolic equivalents.

(continued on next page)

a $P$ value from Wilcoxon test for continuous variables or chi-square for categorical variables. Missing values were not included in $P$ value calculation. Statistically significant $P$ values are in bold.

'Of survivors who received BEP, 170 and 92 were administered BEP $\times 3$ and BEP $\times 4$, respectively.

cAll 159 survivors received EP $\times 4$.

${ }^{\mathrm{d}}$ This category includes 15 patients treated with ifosfamide/etoposide/cisplatin (VIP regimen), 3 patients treated with carboplatin, and 41 patients with other chemotherapy regimens.

eNonwhite race includes: Asian, 19 (3.9\%); black/African American, 6 (1.2\%); American Indian, 1 (0.2\%); more than one race, 9 (1.8\%); and declined to answer/other/ unknown, 40 (8.1\%).

'Vigorous- and moderate-intensity physical activity groups are not mutually exclusive. Nine different activities were surveyed in the Platinum Study, some were moderateintensity and some vigorous-intensity. If a subject reported that he spent 1 hour walking per week (ie, a moderate-intensity activity) and 30 minutes running per week (ie, a vigorous-intensity activity), he was included as a yes for both "any moderate" and "any vigorous" activity 19,20; 3 survivors did not provide data on physical activity.

"One patient without hypogonadism was missing a body mass index value and was not included in the calculation of $P$ value.

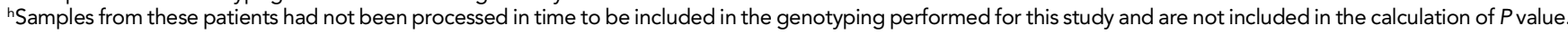




\section{Table 1. Patient Characteristics (cont.)}

\begin{tabular}{|c|c|c|c|c|}
\hline \multirow[b]{2}{*}{ Characteristic } & \multirow{2}{*}{$\begin{array}{l}\text { All Patients } \\
\text { n (\%) }\end{array}$} & \multicolumn{2}{|c|}{ Hypogonadism } & \multirow[b]{2}{*}{$\boldsymbol{P}$ Value $^{\mathrm{a}}$} \\
\hline & & Present, n (\%) & Absent, $\mathrm{n}(\%)$ & \\
\hline \multicolumn{5}{|l|}{ Platinum-based chemotherapy } \\
\hline$E P^{c}$ & $159(32.4)$ & $60(31.7)$ & $99(32.8)$ & \multirow[t]{2}{*}{.95} \\
\hline Other $^{d}$ & $59(12.0)$ & $22(11.6)$ & $37(12.3)$ & \\
\hline \multicolumn{5}{|l|}{ Time since last chemotherapy } \\
\hline Median (range), y & $4.7(0.4-24.2)$ & $4.9(1.0-23.7)$ & $4.4(0.4-24.2)$ & .17 \\
\hline$<2 y$ & $80(16.3)$ & $30(15.9)$ & $50(16.6)$ & \multirow{3}{*}{.82} \\
\hline $2-5 y$ & $219(44.6)$ & $82(43.4)$ & $137(45.4)$ & \\
\hline $6-9 y$ & $75(15.3)$ & $28(14.8)$ & $47(15.6)$ & \\
\hline \multicolumn{5}{|l|}{ Race } \\
\hline White & $416(84.7)$ & $160(84.7)$ & $256(84.8)$ & \multirow{2}{*}{.97} \\
\hline Nonwhite $^{e}$ & $75(15.3)$ & $29(15.3)$ & $46(15.2)$ & \\
\hline \multicolumn{5}{|l|}{ Marital status } \\
\hline Married/Living as married & $295(60.1)$ & $125(66.1)$ & $170(56.3)$ & \multirow{2}{*}{.038} \\
\hline Not married/prefer not to say & $196(39.9)$ & $64(33.9)$ & $132(43.7)$ & \\
\hline \multicolumn{5}{|l|}{ Education } \\
\hline Less than college graduate & $60(12.2)$ & $20(10.6)$ & $40(13.2)$ & \multirow[b]{2}{*}{.67} \\
\hline Some college, college graduate & $318(64.8)$ & $125(66.1)$ & $193(63.9)$ & \\
\hline \multicolumn{5}{|l|}{ Smoking status } \\
\hline Never-smoker & $276(56.2)$ & $103(54.5)$ & $173(57.3)$ & \multirow{3}{*}{.75} \\
\hline Former smoker & 166 (33.8) & $68(36.0)$ & $98(32.5)$ & \\
\hline Current smoker & $47(9.6)$ & $18(9.5)$ & $29(9.6)$ & \\
\hline Not stated & $2(0.4)$ & $0(0)$ & $2(0.7)$ & \\
\hline
\end{tabular}

Abbreviations: BEP, bleomycin/etoposide/cisplatin; EP, etoposide/cisplatin; METs, metabolic equivalents.

(continued on next page)

a $P$ value from Wilcoxon test for continuous variables or chi-square for categorical variables. Missing values were not included in $P$ value calculation. Statistically significant $P$ values are in bold.

bOf survivors who received BEP, 170 and 92 were administered BEP $\times 3$ and BEP $\times 4$, respectively.

'All 159 survivors received EP $\times 4$.

dThis category includes 15 patients treated with ifosfamide/etoposide/cisplatin (VIP regimen), 3 patients treated with carboplatin, and 41 patients with other chemotherapy regimens.

eNonwhite race includes: Asian, 19 (3.9\%); black/African American, 6 (1.2\%); American Indian, 1 (0.2\%); more than one race, 9 (1.8\%); and declined to answer/other/ unknown, $40(8.1 \%)$.

fVigorous- and moderate-intensity physical activity groups are not mutually exclusive. Nine different activities were surveyed in the Platinum Study, some were moderateintensity and some vigorous-intensity. If a subject reported that he spent 1 hour walking per week (ie, a moderate-intensity activity) and 30 minutes running per week (ie, a vigorous-intensity activity), he was included as a yes for both "any moderate" and "any vigorous" activity ${ }^{19,20}$; 3 survivors did not provide data on physical activity.

gOne patient without hypogonadism was missing a body mass index value and was not included in the calculation of $P$ value.

${ }^{h}$ Samples from these patients had not been processed in time to be included in the genotyping performed for this study and are not included in the calculation of $P$ value. 
Table 1. Patient Characteristics (cont.)

\begin{tabular}{|c|c|c|c|c|}
\hline \multirow[b]{2}{*}{ Characteristic } & \multirow{2}{*}{$\begin{array}{l}\text { All Patients } \\
\text { n (\%) }\end{array}$} & \multicolumn{2}{|c|}{ Hypogonadism } & \multirow[b]{2}{*}{$P$ Value ${ }^{a}$} \\
\hline & & Present, n (\%) & Absent, n (\%) & \\
\hline \multicolumn{5}{|c|}{ Average number of alcoholic drinks in past year } \\
\hline Rarely or never & $99(20.2)$ & $43(22.8)$ & $56(18.5)$ & \multirow{4}{*}{.15} \\
\hline$\leq 4$ per week & $219(44.6)$ & $92(48.7)$ & $127(42.1)$ & \\
\hline 5 per week to 1 daily & $109(22.2)$ & $33(17.5)$ & $76(25.2)$ & \\
\hline$\geq 2$ daily & $58(11.8)$ & $21(11.1)$ & $37(12.3)$ & \\
\hline Not stated & $6(1.2)$ & $0(0)$ & $6(2.0)$ & \\
\hline \multicolumn{5}{|c|}{ Moderate-intensity physical activity $(3-6 \mathrm{METs})^{f}$} \\
\hline No & $28(5.7)$ & $15(7.9)$ & $13(4.3)$ & \multirow{2}{*}{.09} \\
\hline Yes & $460(93.7)$ & $173(91.5)$ & $287(95.0)$ & \\
\hline Not stated & $3(0.6)$ & $1(0.5)$ & $2(0.7)$ & \\
\hline \multicolumn{5}{|c|}{ Vigorous-intensity physical activity $(\geq 6 \mathrm{METs})^{\mathrm{f}}$} \\
\hline No & $163(33.2)$ & $82(43.4)$ & $81(26.8)$ & \multirow{2}{*}{$<.001$} \\
\hline Yes & $325(66.2)$ & $106(56.1)$ & $219(72.5)$ & \\
\hline Not stated & $3(0.6)$ & $1(0.5)$ & $2(0.7)$ & \\
\hline \multicolumn{5}{|c|}{ Physical examination and genetic variants } \\
\hline \multicolumn{5}{|l|}{ Body mass index ${ }^{9}$} \\
\hline Median (range), $\mathrm{kg} / \mathrm{m}^{2}$ & $27.7(18.0-52.8)$ & $28.7(18.0-47.7)$ & $27.1(19.6-52.8)$ & $<.001$ \\
\hline$<25 \mathrm{~kg} / \mathrm{m}^{2}$ & $124(25.3)$ & 32 (16.9) & 92 (30.5) & \multirow{2}{*}{$<.001$} \\
\hline$\geq 25 \mathrm{~kg} / \mathrm{m}^{2}$ & $366(74.5)$ & $157(83.1)$ & $209(69.2)$ & \\
\hline \multicolumn{5}{|c|}{ Cumulative number of risk alleles in rs6258 and rs12150660 (SHBG) } \\
\hline 0 or 1 & $176(35.8)$ & $62(32.8)$ & $114(37.7)$ & \multirow{2}{*}{.22} \\
\hline 2 or 3 & $228(46.4)$ & $94(49.7)$ & $134(44.4)$ & \\
\hline Not genotyped ${ }^{h}$ & $87(17.7)$ & $33(17.5)$ & $54(17.9)$ & \\
\hline
\end{tabular}

Abbreviations: BEP, bleomycin/etoposide/cisplatin; EP, etoposide/cisplatin; METs, metabolic equivalents.

${ }^{a} P$ value from Wilcoxon test for continuous variables or chi-square for categorical variables. Missing values were not included in $P$ value calculation. Statistically significant $P$ values are in bold.

bOf survivors who received BEP, 170 and 92 were administered BEP $\times 3$ and BEP $\times 4$, respectively.

${ }^{\mathrm{c} A l l} 159$ survivors received EP $\times 4$.

dThis category includes 15 patients treated with ifosfamide/etoposide/cisplatin (VIP regimen), 3 patients treated with carboplatin, and 41 patients with other chemotherapy regimens.

eNonwhite race includes: Asian, 19 (3.9\%); black/African American, 6 (1.2\%); American Indian, 1 (0.2\%); more than one race, 9 (1.8\%); and declined to answer/other/ unknown, 40 (8.1\%).

fVigorous- and moderate-intensity physical activity groups are not mutually exclusive. Nine different activities were surveyed in the Platinum Study, some were moderateintensity and some vigorous-intensity. If a subject reported that he spent 1 hour walking per week (ie, a moderate-intensity activity) and 30 minutes running per week (ie, a vigorous-intensity activity), he was included as a yes for both "any moderate" and "any vigorous" activity ${ }^{19,20 ;} 3$ survivors did not provide data on physical activity. "One patient without hypogonadism was missing a body mass index value and was not included in the calculation of $P$ value.

hSamples from these patients had not been processed in time to be included in the genotyping performed for this study and are not included in the calculation of $P$ value.

Similar to findings in the general population ${ }^{24-28}$ and in European studies of TCS, ${ }^{29-34}$ TCS with hypogonadism in our study were more likely to report components of metabolic syndrome than TCS with normal testosterone levels. In particular, they were at least 3 times more likely to take medications for high cholesterol levels $(P<.001)$ and almost twice as likely to take medications for high blood pressure $(P=.013)$ and diabetes $(P=.07)$. These observations may explain findings in previous studies that TCS treated with chemotherapy experience up to a 7 -fold increased risk for CVD, with upswings in risk typically observed $\geq 10$ years after therapy. ${ }^{35-39}$ Because the median cohort follow-up time was $<5$ years, we have not yet observed an increase in cardiovascular events among TCS with hypogonadism, but long-term follow-up of all survivors is planned. The association between hypogonadism and peripheral neuropathy was unexpected and may represent a chance finding. However, we previously showed that peripheral sensory neuropathy among TCS is associated with weight gain adjusted for years since treatment $(P=.004) .^{40}$ Thus, it is possible that TCS with significant neuropathy may not be able to 


\begin{tabular}{|c|c|c|c|}
\hline Variable & OR & $95 \% \mathrm{Cl}$ & $P$ Value \\
\hline Age at clinical evaluation, per $10 \mathrm{y}$ & 1.42 & $1.10-1.83$ & .006 \\
\hline \multicolumn{4}{|l|}{ Marital status } \\
\hline Married/Living as married & - & - & Ref \\
\hline Not married & 0.79 & $0.50-1.25$ & .31 \\
\hline \multicolumn{4}{|l|}{ Tumor histology } \\
\hline Seminoma & - & - & Ref \\
\hline Nonseminoma/Mixed & 0.79 & $0.48-1.31$ & .36 \\
\hline \multicolumn{4}{|l|}{ Body mass index } \\
\hline$<25 \mathrm{~kg} / \mathrm{m}^{2}$ & - & - & Ref \\
\hline 25 to $<30 \mathrm{~kg} / \mathrm{m}^{2}$ & 2.08 & $1.18-3.66$ & .011 \\
\hline$\geq 30 \mathrm{~kg} / \mathrm{m}^{2}$ & 2.36 & $1.29-4.31$ & .005 \\
\hline \multicolumn{4}{|c|}{ Vigorous-intensity physical activity ( $\geq 6$ METs) } \\
\hline No & - & - & Ref \\
\hline Yes & 0.66 & $0.41-1.04$ & .07 \\
\hline \multicolumn{4}{|c|}{ Cumulative number of risk alleles in rs6258 and rs 12150660 (SHBG) } \\
\hline 0 or 1 risk alleles & - & - & Ref \\
\hline 2 or 3 risk alleles & 1.45 & $0.95-2.24$ & .09 \\
\hline
\end{tabular}

Abbreviations: GCT, germ cell tumor; METs, metabolic equivalents; OR, odds ratio; TCS, testicular cancer survivors.

aBold indicates ORs with $P<.05$. For the multivariable binary logistic regression analyses, 88 survivors were excluded due to unavailable data for $\geq 1$ variables.

exercise adequately, and consequently develop obesity that increases hypogonadism risk, as it does among men in the general population. ${ }^{7}$ The prevalence of metabolic syndrome in TCS and its risk factors have been reviewed in detail elsewhere. ${ }^{17}$

In our investigation, the cumulative dose of cisplatin did not correlate with the prevalence of hypogonadism. Other studies ${ }^{41,42}$ have reported a higher prevalence of hypogonadism in TCS who received higher doses of cisplatin. Because most patients in the current series (89.1\%) received a cumulative cisplatin dose between 300 and $400 \mathrm{mg} / \mathrm{m}^{2}$, this may explain the lack of correlation observed.

Ohlsson et $\mathrm{al}^{11}$ recently performed a meta-analysis of genome-wide association data in 14,429 men from 7 cohorts in the general population and identified 2 SNPs at the $S H B G$ locus as independently associated with serum testosterone concentration. In our study, these SNPs also appeared to affect testosterone concentration but were of borderline statistical significance. In addition, although the magnitude of influence of these genetic variants on serum testosterone concentration (OR, 1.26 per additional risk allele) in TCS was somewhat less than reported in the general population (OR,

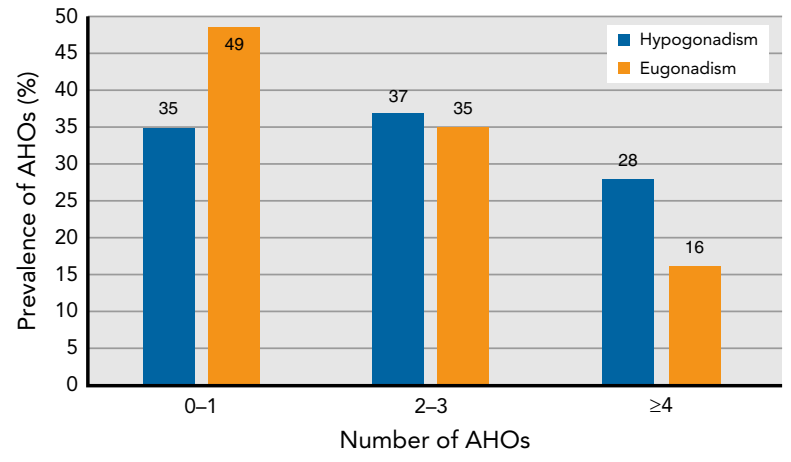

Figure 1. Prevalence of total number of AHOs in TCS and other malignant germ cell tumors with or without hypogonadism. TCS with hypogonadism were more likely to report more AHOs compared with those without. Chi-square test, $P=.002$.

Abbreviations: AHO, adverse health outcome; TCS, testicular cancer survivors.

1.62 per additional risk allele), the $95 \%$ CIs overlapped substantially. In addition, it is possible that other genetic variants, possibly ones that predispose to testicular dysgenesis syndrome (eg, INSL3 and LGR8), ${ }^{43-45}$ may be of higher importance in TCS. As pointed out by Ohlsson et al, ${ }^{11}$ the eventual clinical use of these genetic variants will require further investigation. A critical question is the extent to which these polymorphisms might also influence the eventual development of CVD, and not only mediate low testosterone levels. It is important to note that the prevalence of hypogonadism was substantially higher in our survivors $(38.5 \%)$ compared with subjects included in the meta-analysis by Ohlsson et $\mathrm{al}^{11}$ (13.5\%) (Figure 2). This is despite the fact that the median age of our TCS was only 38 years at the time of clinical evaluation compared with a mean age of 61.7 years for those included in Ohlsson et al. ${ }^{11}$ This places TCS at risk of the complications of hypogonadism for many more decades than men without a history of testicular cancer.

Studies of the effect of testosterone replacement therapy on metabolic abnormalities and CVD risk in TCS are sparse. Investigations in middle-aged and highly functioning older men with no cancer history showed favorable effects on lipid metabolism, bone mineral density, muscle mass, and fat-free body mass. ${ }^{9,10}$ However, evidence regarding the effect of testosterone replacement on CVD risk has been conflicting, ${ }^{46}$ with one clinical trial showing an unexpected increase in adverse CVD events in older men treated with testosterone, ${ }^{47}$ but another series reporting no excess CVD events. ${ }^{48}$ A recent report from the Testosterone Trials (TTrials) group ${ }^{49}$ showed a significantly greater increase in coronary artery noncalcified plaque volume among older men with symptomatic hypogonadism treated with testosterone gel for 1 year compared with placebo. ${ }^{49}$ However, none of these trials ${ }^{47-49}$ was designed 
Table 3. Associations Between AHOs and Hypogonadisma

\begin{tabular}{|c|c|c|c|c|c|}
\hline AHO & Status & All Patients n (\%) & \multicolumn{2}{|c|}{ Hypogonadism } & $P$ Value ${ }^{b}$ \\
\hline $\begin{array}{l}\text { Hypercholesterolemia and on prescription } \\
\text { medication }\end{array}$ & $\begin{array}{l}\text { Yes } \\
\text { No }\end{array}$ & $\begin{array}{r}56(11.4) \\
432(88.0)\end{array}$ & $\begin{array}{r}38(20.1) \\
151(79.9)\end{array}$ & $\begin{array}{c}18(6.0) \\
281(93.0)\end{array}$ & $<.001$ \\
\hline Hypertension and on prescription medication & $\begin{array}{l}\text { Yes } \\
\text { No }\end{array}$ & $\begin{array}{r}67(13.6) \\
419(85.3)\end{array}$ & $\begin{array}{r}35(18.5) \\
152(80.4)\end{array}$ & $\begin{array}{r}32(10.6) \\
267(88.4)\end{array}$ & .013 \\
\hline Erectile dysfunction & $\begin{array}{l}\text { Yes } \\
\text { No }\end{array}$ & $\begin{array}{r}73(14.9) \\
413(84.1)\end{array}$ & $\begin{array}{r}37(19.6) \\
149(78.8)\end{array}$ & $\begin{array}{r}36(11.9) \\
264(87.4)\end{array}$ & .018 \\
\hline Diabetes and on prescription medication & $\begin{array}{l}\text { Yes } \\
\text { No }\end{array}$ & $\begin{array}{c}19(3.9) \\
458(93.3)\end{array}$ & $\begin{array}{c}11(5.8) \\
170(89.9)\end{array}$ & $\begin{aligned} 8 & (2.6) \\
288 & (95.4)\end{aligned}$ & .07 \\
\hline $\begin{array}{l}\text { Psychotropic prescription medications for } \\
\text { anxiety and/or depression }\end{array}$ & $\begin{array}{l}\text { Yes } \\
\text { No }\end{array}$ & $\begin{array}{r}56(11.4) \\
435(88.6)\end{array}$ & $\begin{array}{r}28(14.8) \\
161(85.2)\end{array}$ & $\begin{array}{c}28(9.3) \\
274(90.7)\end{array}$ & .06 \\
\hline Cardiovascular disease & $\begin{array}{l}\text { Yes } \\
\text { No }\end{array}$ & $\begin{aligned} 5 & (1.0) \\
466 & (94.9)\end{aligned}$ & $\begin{array}{c}3(1.6) \\
178(94.2)\end{array}$ & $\begin{array}{c}2(0.7) \\
288(95.4)\end{array}$ & .32 \\
\hline Renal disease & $\begin{array}{l}\text { Yes } \\
\text { No }\end{array}$ & $\begin{array}{c}16(3.3) \\
452(92.1)\end{array}$ & $\begin{aligned} 9 & (4.8) \\
171 & (90.5)\end{aligned}$ & $\begin{aligned} 7 & (2.3) \\
281 & (93.0)\end{aligned}$ & .14 \\
\hline Peripheral neuropathy & $\begin{array}{l}\text { Yes } \\
\text { No }\end{array}$ & $\begin{array}{l}126(25.7) \\
358(72.9)\end{array}$ & $\begin{array}{r}58(30.7) \\
128(67.7)\end{array}$ & $\begin{array}{r}68(22.5) \\
230(76.2)\end{array}$ & .041 \\
\hline Raynaud phenomenon & $\begin{array}{l}\text { Yes } \\
\text { No }\end{array}$ & $\begin{array}{r}91(18.5) \\
393(80.0)\end{array}$ & $\begin{array}{r}42(22.2) \\
146(77.2)\end{array}$ & $\begin{array}{r}49(16.2) \\
247(81.8)\end{array}$ & .11 \\
\hline Benign thyroid disease & $\begin{array}{l}\text { Yes } \\
\text { No }\end{array}$ & $\begin{array}{c}11(2.2) \\
462(94.1)\end{array}$ & $\begin{array}{c}4(2.1) \\
177(93.7)\end{array}$ & $\begin{array}{c}7(2.3) \\
285(94.4)\end{array}$ & .90 \\
\hline Tinnitus & $\begin{array}{l}\text { Yes } \\
\text { No }\end{array}$ & $\begin{array}{l}170(34.6) \\
317(64.6)\end{array}$ & $\begin{array}{r}66(34.9) \\
122(64.6)\end{array}$ & $\begin{array}{l}104(34.4) \\
195(64.6)\end{array}$ & .94 \\
\hline Hearing impairment & $\begin{array}{l}\text { Yes } \\
\text { No }\end{array}$ & $\begin{array}{l}156(31.8) \\
311(63.3)\end{array}$ & $\begin{array}{r}62(32.8) \\
119(63.0)\end{array}$ & $\begin{array}{r}94(31.1) \\
192(63.6)\end{array}$ & .76 \\
\hline
\end{tabular}

Abbreviation: AHO, adverse health outcome.

aDefinitions for AHOs are shown in eTable 2. For some AHOs, data were not always available. Overall, $<5 \%$ of survivors elected not to state whether they had $\geq 1$ of the AHOs; these data were excluded from $P$ value calculations.

${ }^{b}$ Chi-square test was used for calculation of $P$ value. Bold indicates $P$ value $<.05$.

to prospectively assess adverse cardiovascular events, and moreover, these findings may not apply to considerably younger TCS. For young TCS with symptomatic hypogonadism, testosterone replacement should be considered, and future research is needed to stringently address both the benefits and risks of testosterone replacement therapy. Two studies that examine the effect of testosterone replacement versus placebo on CVD risk factors and various biomarkers have recently started recruiting TCS in Europe (ClinicalTrials.gov identifiers: NCT02991209 and NCT03339635). Although results of these trials may provide some insights, the duration of each is $\leq 12$ months, and thus it is unlikely that they will be able to provide information on the risk of CVD outcomes.

\section{Strengths and Limitations}

Strengths of our study include the large number of patients, detailed medical chart abstraction, and evaluation of several risk factors for hypogonadism, including genetic variants. We also used a definition for hypogonadism that is clinically relevant and easily applicable to clinical practice. However, any cross-sectional design has potential limitations and does not allow us to infer causation either of evaluated risk factors to hypogonadism or of hypogonadism to associated AHOs. Although our investigation included many AHOs, by design it was largely focused on cisplatin-related toxicities. Issues such as sexual dysfunction and fertility will be investigated in additional longitudinal follow-up of this cohort. Because blood samples were collected at routine clinic visits, serum testosterone levels were measured only once per patient and did not always occur in the morning as per the recommendation for testosterone testing. Although the SNPs of interest were imputed and not genotyped, they were in perfect linkage disequilibrium with a nearby genotyped SNP. 


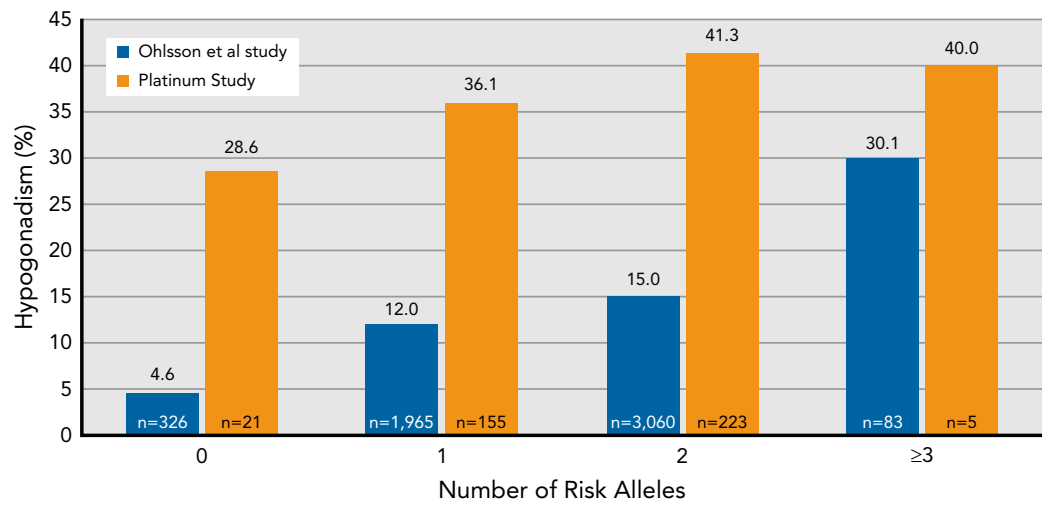

Figure 2. Prevalence of hypogonadism per cumulative number of risk alleles in SHBG in the Platinum Study versus Ohlsson et al. ${ }^{11}$ Percentage of men with hypogonadism among 404 survivors of testicular cancer compared with 5,434 men in the general population included in a metaanalysis by Ohlsson et al, ${ }^{11}$ according to the number of combined risk alleles for rs 12150660 (G) and rs6258 (T) in SHBG. No survivor in the Platinum Study had 4 risk alleles and only 5 survivors had 3 risk alleles. Odds ratio $(\mathrm{OR})$ per each additional risk allele was $1.26(95 \% \mathrm{Cl}, 0.91-1.76 ; P$ for trend $=.17)$. This compares with an OR of 1.62 per risk allele in the general population $\left(95 \% \mathrm{Cl}, 1.41-1.86\right.$; $P$ for trend $\left.=6.5 \times 10^{-12}\right)$.

\section{Conclusions}

At a relatively young age, there is a high prevalence of hypogonadism among North American TCS treated with modern cisplatin-based chemotherapy. Major risk factors include increasing age and obesity. Hypogonadism was strongly associated with risk factors for CVD. The clinical value of assessing possible genetic variants in the role of hypogonadism requires further study before these are recommended for use in the clinic. In the meantime, TCS should be encouraged to maintain a normal body weight and a healthy lifestyle. Although there are currently no evidencebased guidelines, Bhasin et $\mathrm{al}^{50}$ recommend that healthcare providers screen for hypogonadism by surveying TCS for the classic symptoms of hypogonadism (decreased energy, depressed mood, decreased sexual desire and performance, and night sweats $)^{50}$ and prescribe testosterone replacement therapy to survivors who have low testosterone levels on 2 occasions and have symptoms related to low testosterone.
Submitted June 29, 2018; accepted for publication November 21, 2018.

Previous presentation: This study was featured as "News of the Day" press briefing on June 2, 2017, and presented at the 2017 ASCO Annual Meeting June 2-5, 2017; Chicago, Illinois.

Author contributions: Study concept and design: Sesso, Einhorn, Travis. Financial and administrative support: Travis. Provision of study materials or patients: Fung, Feldman, Hamilton, Vaughn, Beard, Einhorn, Travis. Collection and assembly of data: Abu Zaid, Feldman, Cook, Althouse, Travis. Data analysis and interpretation: All authors. Drafting and final approval of manuscript: All authors.

Disclosures: The authors have not received any financial consideration from any person or organization to support the preparation, analysis, results, or discussion of this article.

Funding: This study was funded by the National Cancer Institute (R01 CA157823, to L.B.T.) and the National Institute of General Medical Sciences (U19 GM061390). The NCl had no role in the design of the study; the collection, analysis, or interpretation of data; the writing of the manuscript; or the decision to submit the manuscript for publication

Correspondence: Mohammad Abu Zaid, MD, Bone Marrow and Blood Stem Cell Transplantation, Indiana University, Melvin and Bren Simon Cancer Center, 535 Barnhill Drive, RT 449, Indianapolis, IN 46202.

Email: mabuzaid@iu.edu

\section{References}

1. Nigam M, Aschebrook-Kilfoy B, Shikanov S, et al. Increasing incidence of testicular cancer in the United States and Europe between 1992 and 2009. World J Urol 2015;33:623-631.

2. Verdecchia A, Francisci S, Brenner H, et al. Recent cancer survival in Europe: a 2000-02 period analysis of EUROCARE-4 data. Lancet Oncol 2007;8:784-796.

3. Capocaccia R, Gatta G, Dal Maso L. Life expectancy of colon, breast, and testicular cancer patients: an analysis of US-SEER population-based data. Ann Oncol 2015;26:1263-1268.

4. Travis LB, Beard C, Allan JM, et al. Testicular cancer survivorship: research strategies and recommendations. J Natl Cancer Inst 2010; 102:1114-1130

5. Araujo AB, Esche GR, Kupelian V, et al. Prevalence of symptomatic androgen deficiency in men. J Clin Endocrinol Metab 2007;92:4241-4247.

6. Kaufman JM, Vermeulen A. The decline of androgen levels in elderly men and its clinical and therapeutic implications. Endocr Rev 2005; 26:833-876.

7. Harman SM, Metter EJ, Tobin JD, et al. Longitudinal effects of aging on serum total and free testosterone levels in healthy men. J Clin Endocrinol Metab 2001;86:724-731.
8. Feldman HA, Longcope C, Derby CA, et al. Age trends in the level of serum testosterone and other hormones in middle-aged men: longitudinal results from the Massachusetts male aging study. J Clin Endocrino Metab 2002;87:589-598.

9. Isidori AM, Giannetta E, Greco EA, et al. Effects of testosterone on body composition, bone metabolism and serum lipid profile in middle-aged men: a meta-analysis. Clin Endocrinol (Oxf) 2005;63:280-293.

10. Hildreth $\mathrm{KL}$, Barry DW, Moreau KL, et al. Effects of testosterone and progressive resistance exercise in healthy, highly functioning older men with low-normal testosterone levels. J Clin Endocrinol Metab 2013; 98:1891-1900.

11. Ohlsson C, Wallaschofski $H$, Lunetta $K L$, et al. Genetic determinants of serum testosterone concentrations in men. PLoS Genet 2011;7:e1002313.

12. De Groot LJ, Chrousos G, Dungan K, et al. Testicular cancer pathogenesis, diagnosis and endocrine aspects. In: Feingold KR, Anawalt B, Boyce A, et al, eds. Endotext [internet]. South Dartmouth, MA: MDText.com, Inc.; 2000.

13. Skakkebæk NE, Rajpert-De Meyts E, Main KM. Testicular dysgenesis syndrome: an increasingly common developmental disorder with environmental aspects. Hum Reprod 2001;16:972-978. 
14. Rajpert-De Meyts E. Developmental model for the pathogenesis of testicular carcinoma in situ: genetic and environmental aspects. Hum Reprod Update 2006;12:303-323

15. Fung C, Sesso HD, Williams AM, et al. Multi-institutional assessment of adverse health outcomes among North American testicular cancer survivors after modern cisplatin-based chemotherapy. J Clin Oncol 2017;35:1211-1222.

16. Kerns SL, Fung C, Monahan PO, et al. Cumulative burden of morbidity among testicular cancer survivors after standard cisplatin-based chemotherapy: a multi-institutional study. J Clin Oncol 2018;36:1505-1512.

17. Zaid MA, Gathirua-Mwangi WG, Fung $C$, et al. Clinical and genetic risk factors for adverse metabolic outcomes in North American testicular cancer survivors. J Natl Compr Canc Netw 2018;16:257-265.

18. Taylor HL, Jacobs DR Jr, Schucker B, et al. A questionnaire for the assessment of leisure time physical activities. J Chronic Dis 1978;31:741-755.

19. Chasan-Taber S, Rimm EB, Stampfer MJ, et al. Reproducibility and validity of a self-administered physical activity questionnaire for male health professionals. Epidemiology 1996;7:81-86.

20. Ainsworth BE, Haskell WL, Herrmann SD, et al. 2011 Compendium of Physical Activities: a second update of codes and MET values. Med Sci Sports Exerc 2011;43:1575-1581.

21. Desroches B, Kohn TP, Welliver C, et al. Testosterone therapy in the new era of Food and Drug Administration oversight. Transl Androl Urol 2016;5:207-212.

22. Wheeler HE, Gamazon ER, Frisina R, et al. Variants in WFS1 and other Mendelian deafness genes are associated with cisplatin-associated ototoxicity. Clin Cancer Res 2017;23:3325-3333.

23. Howie B, Fuchsberger C, Stephens M, et al. Fast and accurate genotype imputation in genome-wide association studies through pre-phasing. Nat Genet 2012;44:955-959.

24. Barrett-Connor E, Khaw KT. Endogenous sex hormones and cardiovascular disease in men. A prospective population-based study. Circulation 1988;78:539-545.

25. Khaw KT, Dowsett M, Folkerd E, et al. Endogenous testosterone and mortality due to all causes, cardiovascular disease, and cancer in men: European prospective investigation into cancer in Norfolk (EPIC-Norfolk) prospective population study. Circulation 2007;116:2694-2701.

26. Kupelian V, Hayes FJ, Link CL, et al. Inverse association of testosterone and the metabolic syndrome in men is consistent across race and ethnic groups. J Clin Endocrinol Metab 2008;93:3403-3410.

27. Haring $R$, Völzke $H$, Steveling $A$, et al. Low serum testosterone levels are associated with increased risk of mortality in a population-based cohort of men aged 20-79. Eur Heart J 2010;31:1494-1501.

28. Li C, Ford ES, Li B, et al. Association of testosterone and sex hormonebinding globulin with metabolic syndrome and insulin resistance in men. Diabetes Care 2010;33:1618-1624.

29. de Haas EC, Oosting SF, Lefrandt JD, et al. The metabolic syndrome in cancer survivors. Lancet Oncol 2010;11:193-203.

30. Nuver J, Smit AJ, Wolffenbuttel BH, et al. The metabolic syndrome and disturbances in hormone levels in long-term survivors of disseminated testicular cancer. J Clin Oncol 2005;23:3718-3725.

31. Wethal T, Kjekshus J, Røislien J, et al. Treatment-related differences in cardiovascular risk factors in long-term survivors of testicular cancer. J Cancer Surviv 2007;1:8-16.

32. de Haas EC, Altena R, Boezen HM, et al. Early development of the metabolic syndrome after chemotherapy for testicular cancer. Ann Oncol 2013;24:749-755

33. Willemse PM, Burggraaf J, Hamdy NA, et al. Prevalence of the metabolic syndrome and cardiovascular disease risk in chemotherapy-treated testicular germ cell tumour survivors [published correction appears in $\mathrm{Br}$ Cancer 2013;109:295-296]. Br J Cancer 2013;109:60-67.

34. Haugnes HS, Aass N, Fosså SD, et al. Components of the metabolic syndrome in long-term survivors of testicular cancer. Ann Oncol 2007;18:241-248.

35. Fung C, Fossa SD, Milano MT, et al. Cardiovascular disease mortality after chemotherapy or surgery for testicular nonseminoma: a population-based study. J Clin Oncol 2015;33:3105-3115.

36. Haugnes HS, Wethal T, Aass N, et al. Cardiovascular risk factors and morbidity in long-term survivors of testicular cancer: a 20-year follow-up study. J Clin Oncol 2010;28:4649-4657.

37. Huddart RA, Norman A, Shahidi M, et al. Cardiovascular disease as a longterm complication of treatment for testicular cancer. J Clin Oncol 2003; 21:1513-1523.

38. Meinardi MT, Gietema JA, van der Graaf WT, et al. Cardiovascular morbidity in long-term survivors of metastatic testicular cancer. J Clin Oncol 2000;18:1725-1732.

39. van den Belt-Dusebout AW, de Wit R, Gietema JA, et al. Treatmentspecific risks of second malignancies and cardiovascular disease in 5-year survivors of testicular cancer. J Clin Oncol 2007;25:4370-4378.

40. Dolan ME, El Charif O, Wheeler HE, et al. Clinical and genome-wide analysis of cisplatin-induced peripheral neuropathy in survivors of adultonset cancer. Clin Cancer Res 2017;23:5757-5768.

41. Gerl A, Mühlbayer D, Hansmann G, et al. The impact of chemotherapy on Leydig cell function in long term survivors of germ cell tumors. Cancer 2001;91:1297-1303.

42. Isaksson S, Bogefors K, Ståhl O, et al. High risk of hypogonadism in young male cancer survivors. Clin Endocrinol (Oxf) 2018;88:432-441.

43 Ferlin A, Bogatcheva NV, Gianesello L, et al. Insulin-like factor 3 gene mutations in testicular dysgenesis syndrome: clinical and functional characterization. Mol Hum Reprod 2006;12:401-406.

44. Xing JS, Bai ZM. Is testicular dysgenesis syndrome a genetic, endocrine or environmental disease, or an unexplained reproductive disorder? Life Sci 2018;194:120-129.

45. Foresta C, Ferlin A. Role of INSL3 and LGR8 in cryptorchidism and testicular functions. Reprod Biomed Online 2004;9:294-298.

46. Kloner RA, Carson C III, Dobs A, et al. Testosterone and cardiovascular disease. J Am Coll Cardiol 2016;67:545-557.

47. Basaria S, Coviello AD, Travison TG, et al. Adverse events associated with testosterone administration. N Engl J Med 2010;363:109-122.

48. Srinivas-Shankar U, Roberts SA, Connolly MJ, et al. Effects of testosterone on muscle strength, physical function, body composition, and quality of life in intermediate-frail and frail elderly men: a randomized, double-blind, placebo-controlled study. J Clin Endocrinol Metab 2010;95:639-650.

49. Budoff MJ, Ellenberg SS, Lewis CE, et al. Testosterone treatment and coronary artery plaque volume in older men with low testosterone. JAMA 2017;317:708-716.

50 Bhasin S, Cunningham GR, Hayes FJ, et al. Testosterone therapy in men with androgen deficiency syndromes: an Endocrine Society clinical practice guideline. J Clin Endocrinol Metab 2010;95:2536-2559.

51. Postma TJ, Aaronson NK, Heimans JJ, et al. The development of an EORTC quality of life questionnaire to assess chemotherapy-induced peripheral neuropathy: the QLQ-CIPN20. Eur J Cancer 2005;41:1135-1139.

52. Oldenburg J, Fosså SD, Dahl AA. Scale for chemotherapy-induced longterm neurotoxicity (SCIN): psychometrics, validation, and findings in a large sample of testicular cancer survivors. Qual Life Res 2006;15:791-800.

53. Ventry IM, Weinstein BE. The hearing handicap inventory for the elderly: a new tool. Ear Hear 1982;3:128-134. 
Supplemental online content for:

\section{Adverse Health Outcomes in Relationship to Hypogonadism After Chemotherapy: A Multicenter Study of Testicular Cancer Survivors}

Mohammad Abu Zaid, MD; Paul C. Dinh Jr, MPH; Patrick O. Monahan, PhD; Chunkit Fung, MD; Omar El-Charif, MSc; Darren R. Feldman, MD; Robert J. Hamilton, MD; David J. Vaughn, MD; Clair J. Beard, MD; Ryan Cook, MPH; Sandra Althouse, MS; Shirin Ardeshir-Rouhani-Fard, PharmD, MPH; Howard D. Sesso, ScD; Robert Huddart, MBBS; Taisei Mushiroda, PhD; Michiaki Kubo, MD, PhD; M. Eileen Dolan, PhD; Lawrence H. Einhorn, MD; Sophie D. Fossa, MD, PhD; and Lois B. Travis, MD, ScD; for the Platinum Study Group

J Natl Compr Canc Netw 2019;17(5):459-468

eTable 1: Patient Characteristics in Current Analysis Versus Platinum Study eTable 2: Definitions of Adverse Health Outcomes in the Platinum Study eAppendix 1: The Platinum Study Group eAppendix 2: The Platinum Study Group Advisory Committee 


\section{eTable 1. Patient Characteristics in Current Analysis Versus Platinum Study}

\begin{tabular}{|c|c|c|c|}
\hline Characteristic & $\begin{array}{c}\text { Current Analysis } \\
n(\%)\end{array}$ & $\begin{array}{c}\text { Platinum Study }{ }^{16} \\
\text { n (\%) }\end{array}$ & $P$ Value ${ }^{a}$ \\
\hline Total & $491(100)$ & $1,214(100)$ & \\
\hline Median age at testicular cancer diagnosis (range), y & $30.6(15.4-49.9)$ & $30.5(15.2-60.7)$ & .81 \\
\hline \multicolumn{4}{|l|}{ Clinical characteristics } \\
\hline \multicolumn{4}{|l|}{ Age at clinical evaluation for the Platinum Study } \\
\hline Median (range), y & $38.2(18.7-68.4)$ & $37.4(18.3-74.5)$ & .30 \\
\hline$<30 y$ & $101(20.6)$ & $273(22.5)$ & \multirow{5}{*}{.74} \\
\hline $30-39 y$ & $168(34.2)$ & $436(35.9)$ & \\
\hline $40-49$ y & $139(28.3)$ & $313(25.8)$ & \\
\hline$\geq 50 y$ & $82(16.7)$ & $190(15.7)$ & \\
\hline Missing & $1(0.2)$ & $2(0.2)$ & \\
\hline \multicolumn{4}{|l|}{ Tumor histology } \\
\hline Seminoma & $130(26.5)$ & $310(25.5)$ & \multirow{2}{*}{.73} \\
\hline Nonseminoma/Mixed & $361(73.5)$ & $904(74.5)$ & \\
\hline \multicolumn{4}{|l|}{ Tumor site } \\
\hline Testis & $438(89.2)$ & $1,078(88.9)$ & \multirow{2}{*}{.81} \\
\hline Extragonadal & $53(10.8)$ & $135(11.1)$ & \\
\hline \multicolumn{4}{|l|}{ Cumulative dose of cisplatin, $\mathrm{mg} / \mathrm{m}^{2}$} \\
\hline$<300$ & $28(5.7)$ & $61(5.0)$ & \multirow{6}{*}{.28} \\
\hline 300 & $155(31.6)$ & $447(36.8)$ & \\
\hline $301-399$ & $17(3.5)$ & $44(3.6)$ & \\
\hline 400 & $265(54.0)$ & $589(48.5)$ & \\
\hline$>400$ & $23(4.7)$ & $55(4.5)$ & \\
\hline Not available & $3(0.6)$ & $18(1.5)$ & \\
\hline \multicolumn{4}{|l|}{ Cumulative dose of bleomycin, IU } \\
\hline 0 & $198(40.3)$ & $482(39.7)$ & \multirow{5}{*}{.16} \\
\hline$>0-180,000$ & $37(7.5)$ & $66(5.4)$ & \\
\hline $181,000-270,000$ & $183(37.3)$ & $477(39.3)$ & \\
\hline $271,000-360,000$ & $72(14.7)$ & $175(14.4)$ & \\
\hline$>360,000$ & $1(0.2)$ & $14(1.2)$ & \\
\hline \multicolumn{4}{|l|}{ Sociodemographic characteristics } \\
\hline \multicolumn{4}{|l|}{ Race } \\
\hline White & $416(84.7)$ & $1,036(85.3)$ & \multirow{2}{*}{.78} \\
\hline Nonwhite & 75 (15.3) & $178(14.7)$ & \\
\hline \multicolumn{4}{|l|}{ Marital status } \\
\hline Married/Living as married & $295(60.1)$ & $740(61.0)$ & \multirow{2}{*}{.86} \\
\hline Not married/prefer not to say & $196(39.9)$ & $474(39.0)$ & \\
\hline \multicolumn{4}{|l|}{ Education } \\
\hline Less than college graduate & $60(12.2)$ & $138(11.4)$ & \multirow{3}{*}{.79} \\
\hline Some college, college graduate & $318(64.8)$ & $786(64.7)$ & \\
\hline Postgraduate level & $104(21.2)$ & $273(22.5)$ & \\
\hline Other/Prefer not to say & $9(1.8)$ & $17(1.4)$ & \\
\hline
\end{tabular}

Abbreviation: METs, metabolic equivalents.

(continued on next page)

a $P$ value from Wilcoxon test for continuous variables or chi-square for categorical variables. Missing values were not included in $P$ value calculation.

bTumor site data were not available for 1 patient in the Platinum Study.

cVigorous- and moderate-intensity physical activity groups are not mutually exclusive. Nine different activities were surveyed in the Platinum Study, some were moderateintensity and some vigorous-intensity. If a subject reported that he spent 1 hour walking per week (ie, a moderate-intensity activity) and 30 minutes running per week (ie, a vigorous-intensity activity), he was included as a yes for both "any moderate" and "any vigorous" activity ${ }^{19,20 ;} 4$ survivors did not provide data on physical activity. 


\section{eTable 1. Patient Characteristics in Current Analysis Versus Platinum Study (cont.)}

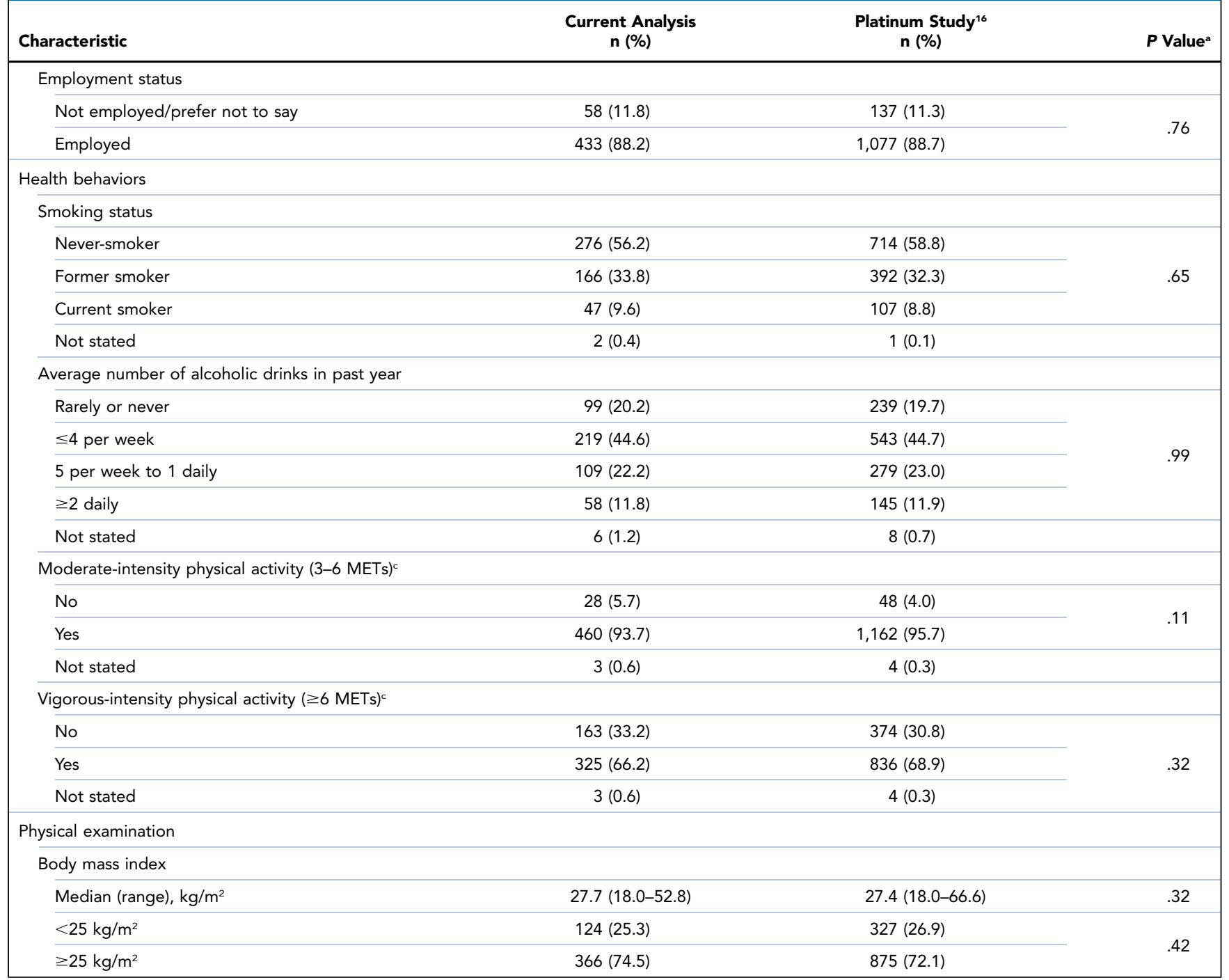

Abbreviation: METs, metabolic equivalents.

a $P$ value from Wilcoxon test for continuous variables or chi-square for categorical variables. Missing values were not included in $P$ value calculation.

bTumor site data were not available for 1 patient in the Platinum Study.

'Vigorous- and moderate-intensity physical activity groups are not mutually exclusive. Nine different activities were surveyed in the Platinum Study, some were moderateintensity and some vigorous-intensity. If a subject reported that he spent 1 hour walking per week (ie, a moderate-intensity activity) and 30 minutes running per week (ie, a vigorous-intensity activity), he was included as a yes for both "any moderate" and "any vigorous" activity ${ }^{19,20}$; 4 survivors did not provide data on physical activity. 


\section{eTable 2. Definitions of Adverse Health Outcomes in the Platinum Study}

1. Hypercholesterolemia and on prescription medication: Answered "yes, current" to the following question: have you ever taken prescription medications for high cholesterol.

2. Hypertension and on prescription medication: Answered "yes" to (1) have you ever been diagnosed with high blood pressure, and "yes, current" to (2) have you ever taken prescription medications for high blood pressure (including current use).

3. Erectile dysfunction: Answered "quite a bit" or "very much" to the following question: getting or maintaining an erection, a or if they received medication for erectile dysfunction.

4. Diabetes and on prescription medication: Answered "yes" to either of the following questions: (1) diabetes requiring insulin, or (2) diabetes requiring tablets or pills.

5. Psychotropic prescription medications for anxiety and/or depression: Reported using anxiolytic, antidepressant, or stimulant medications.

6. Cardiovascular disease: Answered "yes" to any of the following:

a. Coronary artery disease: Answered "yes" to any of the following questions: (1) coronary artery disease, (2) angioplasty or stent placement, (3) coronary bypass surgery, or (4) heart attack or myocardial infarction.

b. Heart failure: Answered "yes" to heart failure.

c. Cerebrovascular disease: Answered "yes" to any of the following questions: (1) mini-stroke (transient ischemic attack), (2) stroke, or (3) carotid artery surgery.

7. Peripheral vascular disease: Answered "yes" to either of the following questions: (1) pain in calf (lower leg) when walking (intermittent claudication), or (2) surgery in the artery in your pelvis or legs (peripheral artery surgery).

8. Thromboembolic disease: Answered "yes" to either of the following questions: (1) blood clot(s) in leg (deep venous thrombosis) and taking an anticoagulant, or (2) blood clot(s) in lung (pulmonary embolism) and taking an anticoagulant.

9. Renal disease: Answered "yes" to kidney disease (renal disease).

10. Peripheral neuropathy: Answered "quite a bit" or "very much" to any of the following questions: (1) tingling in fingers or hands, ${ }^{\text {a }}$ (2) tingling in toes or feet, (3) numbness in fingers or hands, ${ }^{a}(4)$ numbness in toes or feet, ${ }^{a}(5)$ shooting/burning pain in fingers or hands, ${ }^{a}(6)$ shooting/burning pain in toes or feet, ${ }^{a}$ (7) pain and tingling in fingers or hands, ${ }^{b}$ or (8) pain and tingling in toes or feet. ${ }^{b}$

11. Raynaud phenomenon: Answered "quite a bit" or "very much" to any of the following questions: (1) white/cold hands/fingers when it is cold, or (2) white/cold feet/toes when it is cold. ${ }^{\text {b }}$

12. Benign thyroid disease: Answered "yes" to either of the following questions: (1) overactive thyroid (hyperthyroidism), or (2) underactive thyroid (hypothyroidism).

13. Tinnitus: Answered "yes" to any of the following questions: (1) "quite a bit" or "very much" ringing in ears, or (2) ringing or buzzing in ears.

14. Hearing impairment: Answered "yes" to any of the following questions: (1) "quite a bit" or "very much" for difficulty hearing, (2) "quite a bit" or "very much" reduced hearing, ${ }^{b}(3)$ problems hearing words, sounds, or language in crowds, ${ }^{c}$ (4) require hearing aid, ${ }^{c}$ or (5) complete deafness. ${ }^{c}$

15. Problems with balance/vertigo/dizziness: Answered "yes" to any of the following questions: (1) "quite a bit" or "very much" dizzy when standing up, or (2) persistent dizziness or vertigo.

a Question is from the EORTC Quality of Life - Chemotherapy-Induced Peripheral Neuropathy questionnaire. ${ }^{51}$

${ }^{b}$ Question is from the Scale for Chemotherapy-Induced Long-Term Neurotoxicity (SCIN). ${ }^{52}$

'Question is derived from the Hearing Handicap Inventory for the Elderly (HHIE). ${ }^{53}$ 
4 - Abu Zaid et al

\section{eAppendix 1. The Platinum Study Group}

Howard D. Sesso ${ }^{1}$; Clair J. Beard ${ }^{2}$; Stephanie Curreri²; Lois B. Travis ${ }^{3}$; Lawrence H. Einhorn ${ }^{3}$; Mary Jacqueline Brames ${ }^{3}$; Kelli Norton ${ }^{3}$; Darren R. Feldman ${ }^{4}$; Erin Jacobsen ${ }^{4}$; Deborah Silber ${ }^{4}$ Rob Hamilton ${ }^{5}$; Lynn Anson-Cartwright ${ }^{5}$; Nancy J. Cox ${ }^{6}$ Eric Gamazon ${ }^{6}$; M. Eileen Dolan ${ }^{7}$; Omar El-Charif $;$ David J. Vaughn ${ }^{8}$; Linda Jacobs ${ }^{8}$; Donna Pucci ; Debbie Baker ${ }^{9}$ Cindy Casaceli ${ }^{9}$ Chunkit Fung; ; Eileen Johnson ${ }^{9}$; and Robert D. Frisina ${ }^{10}$

${ }^{1}$ Brigham and Women's Hospital, Boston, Massachusetts

${ }^{2}$ Dana-Farber Cancer Institute, Boston, Massachusetts

${ }^{3}$ Indiana University, Bloomington, Indiana

${ }^{4}$ Memorial Sloan Kettering Cancer Center, New York, New York

${ }^{5}$ Princess Margaret Cancer Center, Toronto, Ontario, Canada

${ }^{6}$ Vanderbilt University, Nashville, Tennessee

${ }^{7}$ University of Chicago, Chicago, Illinois

${ }^{8}$ University of Pennsylvania, Philadelphia, Pennsylvania

${ }^{9}$ University of Rochester, Rochester, New York

${ }^{10}$ University of South Florida, Tampa, Florida 


\section{eAppendix 2. The Platinum Study Group Advisory Committee}

George Bosll'; Sophie D. Fossa ${ }^{2}$; Mary Gospodarowicz ${ }^{3}$; Leslie L. Robison ${ }^{4}$; and Steven E. Lipshultz ${ }^{5}$

${ }^{1}$ Memorial Sloan Kettering Cancer Center, New York, New York

${ }^{2}$ Norwegian Radium Hospital, Oslo, Norway

${ }^{3}$ Princess Margaret Hospital, Toronto, Ontario, Canada

${ }^{4}$ St. Jude Children's Research Hospital, Memphis, Tennessee

${ }^{5}$ Wayne State University, Detroit, Michigan 